International scientific and technical conference

DOI: $10.34185 / 1991-7848 . i t m m .2020 .01 .037$

\title{
СОЦИО-ТЕХНИЧЕСКИЕ СИСТЕМЫ (СТС) КАК НОВАЯ ПАРАДИГМА КОМПЬЮТЕРИЗАЦИИ
}

Косолапов А.А.

Днепровский национальный университет железнодорожного транспорта имени акад. В. Лазаря на, Украина

КлючевЫе слова: СОЦИО-ТЕХНИЧЕСКИЕ СИСТЕМЫ, СТС, ПАРАДИГМА, КОМПЬЮТЕРИЗАЦИЯ.

Глобальное информационное общество. Вопросам философскоантропологического осмысления изменений, происходящих в обществе в условиях его спонтанной компьютеризации и информатизации, уделяется большое внимание, начиная с момента появления первого компьютера (1944 г.), выполняющего автоматизированную обработку цифровой информации по заложенной в него программе, до настоящего времени. Как отмечает М. Кастельс, «в конце двадцатого столетия мы переживаем один из редких в истории моментов. Момент этот характеризуется трансформацией нашей «материальной культуры» через работу новой технологической парадигмы, построенной вокруг информационных технологий». В итоге, все происходящие изменения были задекларированы на межгосударственном, планетарном уровне. 22 июля 2000 г. в Японии во время встречи лидеров "Группы восьми" была принята Окинавская Хартия Глобального Информационного Общества, в которой отмечается, что «...информационно-коммуникационные технологии (ИКомТ) являются одним из наиболее важных факторов, влияющих на формирование общества двадцать первого века. Их революционное воздействие касается образа жизни людей, их образования и работы, а также взаимодействия правительства и гражданского общества». ИКомТ стимулирует экономическую и социальную трансформацию, которая заключается «в способности содействовать людям и обществу в использовании знаний и идей». А устойчивость такого глобального информационного общества «основывается на стимулирующих развитие человека демократических ценностях, таких как свободный обмен информацией и знаниями, взаимная терпимость и уважение к особенностям других людей». В 
Ministry of Education and Science of Ukraine

The National Metallurgical Academy of Ukraine, Dnipro, 17 - 19 March, 2020

этом документе записаны те ожидаемые позитивные изменения в информационном сообществе, на которых мы не будем останавливаться.

Попробуем определить или уточнить основные базовые понятия ИКомТ, основанные на структурированном, синергетическом, антропоцентрическом понятии «архитектура» информационной системы (АИС) и предложить гносеологическую модель эволюции парадигм компьютеризации и информатизации как результат развития $А И С$, для которых выбраны три основные характеристики, изменение которых приводит к смене предложенных парадигм. Для каждого из этапов развития информационнокомпьютерных технологий рассматриваются рождаемые проблемы антропологического характера, то есть речь будет идти об «обратной стороне медали» - о цивилизационных проблемах новых ИКомТ.

Взяться за данную работу меня, «технаря», учёного, который более 30-лет работает в сфере компьютеризации и информатизации и является свидетелем смены всех поколений электронных вычислительных машин (ЭВМ), который читает много лет в университете курсы по компьютерным системам, Интернет-технологиям, WWW-системам (о Всемирной паутине), искусственному интеллекту, системному проектированию. который более 15 лет преподаёт информатику в техническом лицее, который видит «некорректность» некоторых базовых понятий и определений при философском анализе антропологических проблем информатизации, и который всегда, со студенческой скамьи, интересовался философскоантропологическими вопросами роли компьютеров в жизни человека и общества меня подтолкнуло знакомство с рядом работ, связанных с философско-антропологическими проблемами информатизации, в которых авторы-философы были некорректны в используемых определениях и рассуждениях с точки зрения ИКомТ.

В основе полученных выводов лежат результаты эмпирического изучения и содержательно-смыслового анализа дискурсивного (речевого) мышления и развертывания рефлексии школьников и студентов в процессе решения ими творческих задач (1-11 классы школы и 1-5 курсы технического университета). Влияние ИКомТ выражается в трансформации личности, её интеллектуальных, 
International scientific and technical conference Information Technologies in Metallurgy and Machine building - ITMM 2020

логических способностей, в изменении мировосприятия, в «мутации» языка и культуры поведения. В работе также использовался системно-деятельностный подход, который дает возможность выявить и проанализировать влияние основных компонентов ИКомТ на образовательную деятельность и представить их как единую систему человеческой деятельности. В работе использовались философские принципы: всестороннего рассмотрения предмета, единства логического и исторического, восхождения от абстрактного к конкретному. Применялись общенаучные принципы: системного единства и развития, декомпозиции и иерархичности, индивидуализации и кооперации, многообразия и таксономии и др.

В настоящее время существует много подходов к толкованию, что представляет собой информационное общество (ИнО). Наиболее полное его описание дал британский социолог Ф. Уэбстер в своей книге «Теории информационного общества». Он выделил пять критериев (признаков) ИнО: 1 - технологический критерий (развитие технологий изготовления электронных устройств); 2 - экономический критерий (более высокая эффективность ИКомТ по сравнению с другими отраслями экономики); 3 - расширение занятости населения в сфере информационных технологий; 4 - пространственный критерий (использование сетевых технологий и Интернет); 5 - критерий формирования информационной культуры. Л. Караваев считает, что смыслообразующим понятием информационного общества является автоматизация информационных процессов. Последнее утверждение, на мой взгляд, является ошибочным, ибо автоматизация обработки информации была реализована уже в ЭВМ первого поколения в 1944 году, хотя об информационном обществе заговорили только в начале текущего столетия.

Попытаемся определиться, когда компьютеризация эволюционировала в информатизацию общества, и какова роль человека в этих процессах. Для этого рассмотрим, не усложняя специальными терминами, насколько это возможно, те компоненты, которые не изменяются уже в течении десятков лет в пяти поколениях ЭВМ с 1944 по 2015 год (в больших ЭВМ, в серверах, в 
персональных компьютерах, планшетах, смартфонах). Для этого рассмотрим понятие «архитектура» ЭВМ или информационной системы.

Смена парадигм компьютеризации. Паради́гму будем рассматривать как совокупность явных и неявных (и часто не осознаваемых) предпосылок, определяющих научные исследования и признанных на данном этапе развития науки, а также универсальный метод принятия эволюционных решений. В данном случае это гносеологическая модель развития процессов информатизации, которая представлена на рис. 1. В настоящее время можно говорить о переходе от парадигмы информационных систем к парадигме интеллектуальных систем. Смена парадигм опирается на изменение приоритетов технических и антропологических требований к исследуемым системам. Рассмотрим приведенные парадигмы, как изменяется состав их видов обеспечения, а также как при этом трансформируются и дополняются антропологические проблемы.

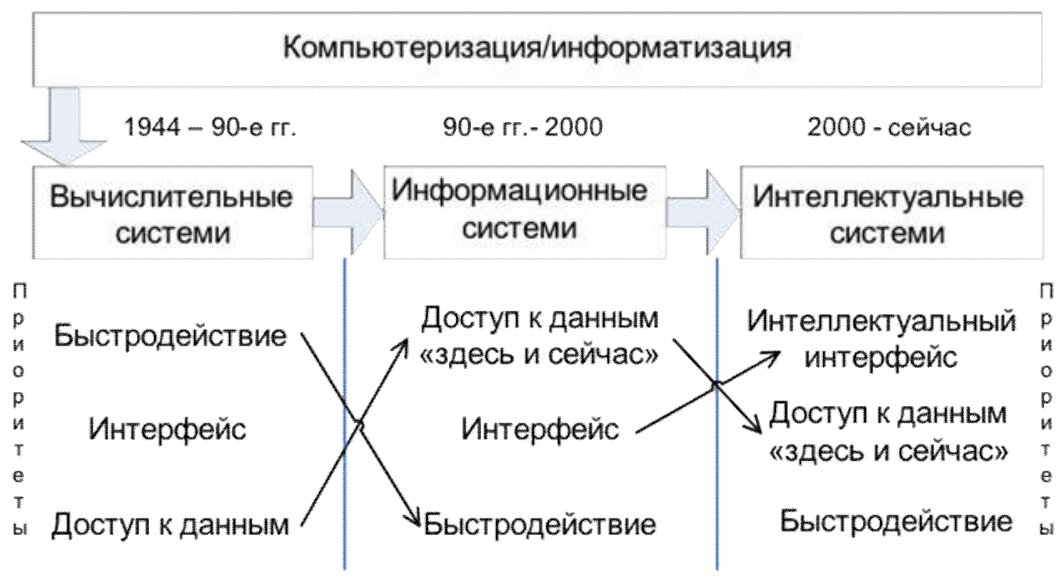

Рисунок 1 - Эволюция парадигм компьютеризации

Архитектура социо-технической системы (CTC). АИС представляет собой множество взаимосвязанных структур, которые описываются следующим выражением:

$$
\begin{aligned}
& A И C=Ц е л ь \cap(K T C \cup \Pi O \cup M O \cup И O \cup \pi O \cup O O \cup M e m p O), \\
& \cup \text { операция объединения множеств, } \\
& \cap \text { операция пересечения множеств, }
\end{aligned}
$$

в которой человек или некоторый социум представлены компонентой $O O$.

Рассмотрены основные проблемы социума в условиях информатизации. Приедены примеры структур ресурсного обеспечения парадигм компьютеризации. (Рис.2) 


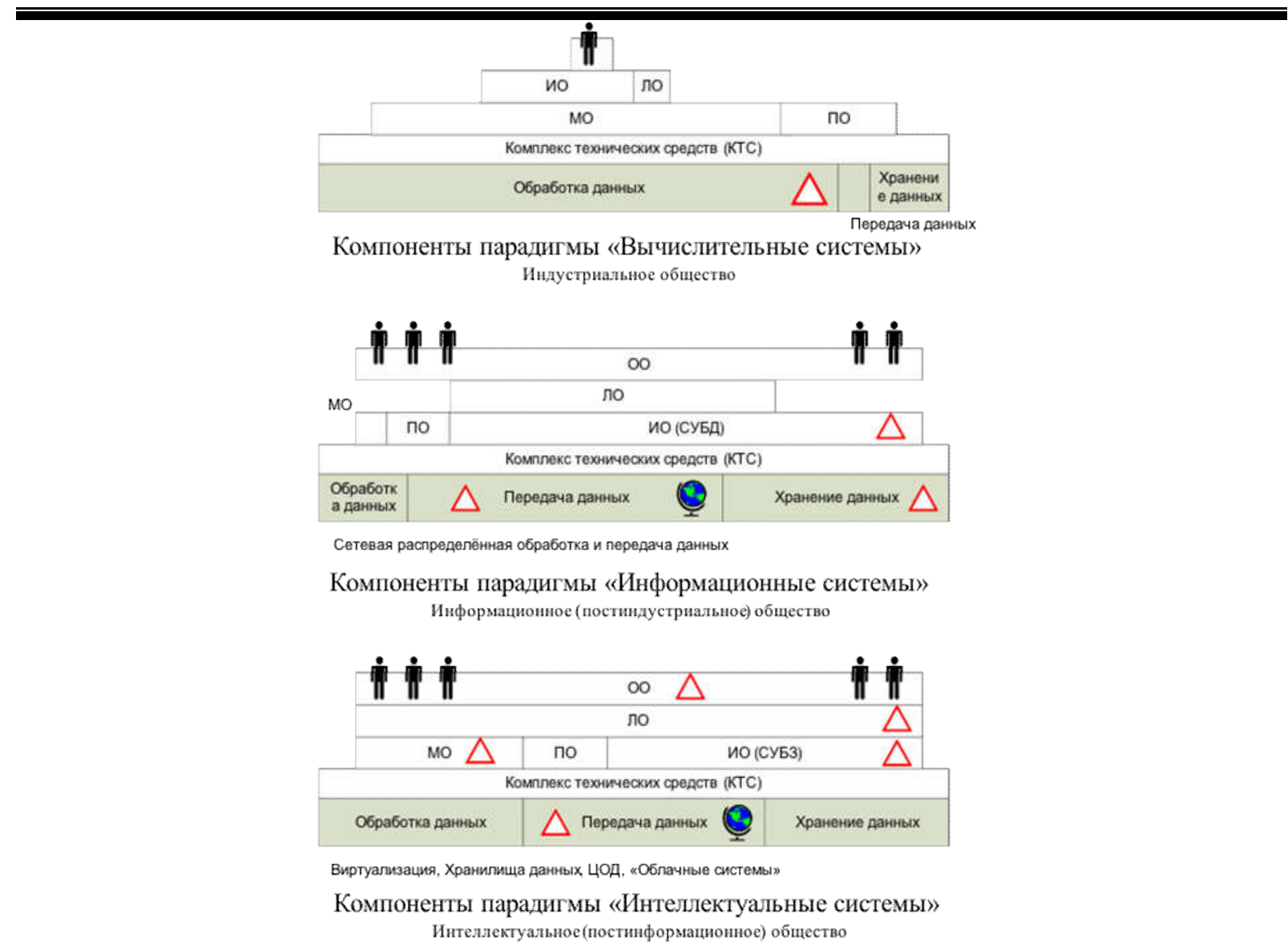

Рисунок 2 - Примеры структур ресурсного обеспечения парадигм компьютеризации

\section{SOCIO-TECHNICAL SYSTEMS (STS) AS A NEW PARADIGM OF COMPUTERIZATION}

Kosolapov Anatolii

Abstract. The paper considers the problems of the formation of modern global society and their impact on the development of computerization paradigms. At present, a new paradigm is emerging - socio-technical systems (STS) as the development of the paradigm of intelligent systems. The author has proposed a new definition of STS through the classical definition of the concept of the architecture of a socio-technical system, including an 8-link formula from all the main types of resource support for computer systems: a set of hardware (HRS), mathematical (MRS) and software (SRS) resource support, information (IRS) and linguistic (LRS), metrological (MetRS) and documentary (DRS) support and organizational support (ORS) or human resource of STS. In work the structure of resource support for computerization paradigms is given. The transition to STS is associated with the need to solve a number of pressing problems of society in the context of global informatization.

Key words: SOCIO-TECHNICAL SYSTEMS, STS, PARADIGM, COMPUTERIZATION. 